\title{
A correlation analysis of miRNA-34a and its predicted target genes in leukemia
}

\author{
RUIHONG TANG ${ }^{1}$, JUANJUAN LI ${ }^{1}$, MEI YUE ${ }^{1}$, ZIQIN LIU $^{1}$, SHUNQIAO FENG ${ }^{1}$, \\ SUOQIN TANG ${ }^{2}$ and TIANYOU WANG ${ }^{1}$ \\ ${ }^{1}$ Department of Hematology, Capital Institute of Pediatrics-Affiliated Children's Hospital, Beijing 100020; \\ ${ }^{2}$ Department of Pediatrics, PLA General Hospital, Beijing 100853, P.R. China
}

Received August 3, 2013; Accepted January 21, 2014

DOI: $10.3892 / \mathrm{mmr} .2014 .1931$

\begin{abstract}
RNA-34a (miRNA-34a) plays an important role in the pathogenesis of leukemia. This study aimed to explore its role in the proliferation of HL-60 cells and the correlation with some of its predicted target genes: the cyclin-dependent kinase $4(C D K 4)$, the oncogene $M Y B$ and the silent information regulator 1 (SIRT1). We first analyzed the expression of miR-34a, CDK4, MYB and SIRT1 in peripheral blood samples from acute leukemia (AL) patients and healthy controls, and conducted a correlation analysis. HL-60 cells were then transfected with miR-34a and control 'scramble' miRNA, and quantitative RT-PCR and western blotting were used to analyze the effects of the interfering sequence in HL-60 cells. The expression of miR-34a was significantly reduced in AL patients compared to healthy controls $(\mathrm{P}<0.01)$, and negatively correlated with the expression of $C D K 4$ and $M Y B$. Sub-group analysis revealed that the expression of $M Y B$ was significantly lower in AL children $<3$ years old compared to those $>3$ years. Following the transfection of HL- 60 cells with miR-34a, the mRNA level of $C D K 4, M Y B$ and SIRTI decreased by $53.2,43.3$ and $33.5 \%$, respectively, compared to the control, similarly to the respective changes in protein levels. This study showed that the expression of miR-34a negatively correlates with the expression of $C D K 4$ and $M Y B$ in pediatric patients with acute leukemia. miRNA-34a downregulates the expression of the $C D K 4, M Y B$ and SIRT1 genes in vitro; it may thus represent a novel therapeutic target for acute leukemia.
\end{abstract}

\section{Introduction}

The microRNA-34 (miR-34) family comprises three homologous molecules, miR-34a, miR-34b and miR-34c. Previous studies have demonstrated that p53 regulates the

Correspondence to: Dr Tianyou Wang, Department of Hematology, Capital Institute of Pediatrics-Affiliated Children's Hospital, 2 Yabao Road, Beijing 100020, P.R. China

E-mail: wangty999@sohu.com

Key words: microRNA-34a, leukemia, HL-60 cells, cyclin-dependent kinase 4, MYB transcription of miR-34a, and that miR-34a is involved in the p53 pathway (1-4). Members of the miR-34 family have been widely suggested to act as important tumor suppressors and mediators of p53 effects (5-9). Reduced miR-34a expression is also observed in leukemia-related thrombocythemia, polycythemia, and primary myelofibrosis. He et al (10) showed that cyclin E2 (CCNE2), cyclin-dependent kinase 4 (CDK4) and the hepatocyte growth factor receptor $(M E T)$ genes are targets of miR-34a. Navarro et al (11) reported that miR-34a directly regulates the expression of $M Y B$, facilitating megakaryocyte differentiation, and the expression of $C D K 4$ and CDK6, to inhibit the $G_{1} / S$ cell cycle transition. Yamakuchi et al (5) showed that miR-34a-mediated repression of the expression of the silent information regulator 1 gene (SIRT1) leads to an increase in acetylated p53 and expression of $p 21$ and PUMA, transcriptional targets of p53 that regulate the cell cycle and apoptosis, respectively. The levels of miR-34s are reported to be undetectable or reduced in various types of cancer, including nasopharyngeal carcinoma, gastric, pancreatic and prostate cancer, retinoblastoma and leukemia (12-17).

The human promyelocytic cell line HL60, derived from an acute promyelocytic leukemia patient, provides a continuous source of human cells for studying the molecular events of myeloid differentiation and the effects of physiologic, pharmacologic, and virologic elements in this process (18). The expression of $C D K 4, M Y B$ and SIRT1 in peripheral blood samples collected from children with or without acute myelogenous leukemia was examined, as well as the correlation between the expression of miRNA-34a and that of $C D K 4$, $M Y B$ and SIRT1. Then, the interfering miRNA-34a was used to downregulate the expression of $C D K 4, M Y B$ and SIRT1 in the HL-60 cell line, in order to further investigate its role in regulation of these genes in AL.

\section{Materials and methods}

Ethical considerations. The study was approved by the Ethics Committee of the Capital Institute of Pediatrics-Affiliated Children's Hospital in May 2011, which approved the blood sample extraction and data collection procedures. All the experiments were undertaken following the provisions of the Declaration of Helsinki. Written informed consent was obtained from the children's parents. 
Subjects. A total of 29 pediatric patients ( 12 male and 17 female) with acute leukemia (AL) were recruited from the Hematology Department of the Capital Institute of Pediatrics-Affiliated Children's Hospital and the Department of Pediatrics in the General Hospital of the Chinese PLA between February and November, 2011. These AL patients had a median age of 5.1 years (range, 1-13.5 years), and were diagnosed with acute leukemia based on the morphologic, immunologic and cytogenetic (MIC) system, where the morphologic test was conducted on bone marrow cells. Patients with the AML-M3 subtype of AL were not included in this study. All the patients were diagnosed within 7 days, with 25 diagnosed with acute lymphoblastic leukemia [7 high risk (HR), 7 intermediate risk (IR) and 15 standard risk (SR) cases] and the remaining 4 patients diagnosed with acute myeloid leukemia. Twenty-one age-matched healthy children were recruited as controls. Clinical information on all the participants, including age, gender, peripheral white blood cell (WBC) count, MIC classification and response to prednisone was recorded (Table I), and all the patients were divided into subgroups based on the above parameters to analyze the associations between these factors and CDK4, MYB and SIRT1 expression.

Blood samples and RNA extraction. A total of $3 \mathrm{ml}$ of peripheral blood was collected from the participants of each group. Heparin $(10 \mathrm{IU} / \mathrm{ml})$ was used for anticoagulation, and mononuclear cells were isolated by lymphocyte separation solution (Huamei Biotechnology Co., Beijing, China). Total RNA was isolated using the TRIzol reagent (Invitrogen Life Technologies, Carlsbad, CA, USA) following the manufacturer's protocol.

miRNA-34a expression analysis. Isolation of peripheral blood mononuclear cells (PBMCs) from blood of AL patients was achieved by centrifugation in a Ficoll gradient as previously described (19). After washing with phosphate-buffered saline (PBS), cells were resuspended in RPMI-1640 medium to a final concentration of $1 \times 10^{7}$ cells $/ \mathrm{ml}$. Total RNA samples extracted from PBMCs were reverse transcribed and quantitative PCR (qPCR) was performed on the resulting cDNA to determine the level of miR-34a using a ReverTra Ace ${ }^{\circledR}$ qPCR RT Kit (Toyobo Co., Ltd., Osaka, Japan) and ABI 7500 real-time PCR system (Applied Biosystems, Foster City, CA, USA). The expression of the small RNA RNU6B was used as internal reference for normalization. miR-34a Primers were synthesized as follows: forward, CTTGAACTCCTGGGGCCTGAAG; reverse, GCCAAAGAAACACTCACAGCT. Amplifi cation consisted of 2 min at $95^{\circ} \mathrm{C}$, followed by 40 cycles of $95^{\circ} \mathrm{C}$ for $15 \mathrm{sec}$ and $60^{\circ} \mathrm{C}$ for $30 \mathrm{sec}$. Melting curve analysis was performed at the end of the PCR cycles in order to validate the specificity of the expected PCR product. All samples were run in duplicate, including blank controls without cDNA. The cycle threshold $(\mathrm{Ct})$ was defined as the number of cycles required for the fluorescent signal to cross the threshold in qPCR. The formula $2^{\Delta \mathrm{Ct}}$ was used to calculate the levels of miRNAs in the serum, where $\Delta \mathrm{Ct}=$ mean (Ct of internal references) - Ct of target miRNA.

Cell culture and in vitro transfection. Human HL-60 cells were purchased from the American Type Culture Collection (ATCC; Manassas, VA, USA). Cells were maintained in RPMI-1640 medium (Neuronbc, Beijing, China) supplemented with $10 \%$ fetal bovine serum (FBS) from HyClone Laboratories, Inc. (Logan, UT, USA) and were kept under $5 \% \mathrm{CO}_{2}$ at $37^{\circ} \mathrm{C}$. Three groups were defined for the in vitro experiments: i) test group, in which cells were transfected with a sequence specific to miRNA-34a (pre-miR34a); ii) negative control (NC) group, transfected with scrambled miRNA; iii) blank control (BC) group, where cells were not transfected.

Transient transfection of cells was performed on six-well plates, using the following sequences (Invitrogen Life Technologies, Grand Island, NY, USA): pre-miRNA34a, 5'-UGG CAG UGU CUU AGC UGG UUG U-3'; scrambled miRNA, 5'-UCA CAA CCU CCU AGA AAG AGU AGA-3'. The Lipofectamine ${ }^{\circledR}$ RNAiMAX transfection reagent (Invitrogen Life Technologies) was used according to the manufacturer's instructions. A total of $5 \mu \mathrm{l}$ Lipofectamine was used for transfection of $30 \mathrm{nM}$ miRNA (pre-miRNA34a or scrambled) per well.

Target gene expression analysis. After $48 \mathrm{~h}$ of transfection, total RNA was extracted, and first strand (cDNA) was synthesized using the ReverTra Ace ${ }^{\circledR}$ reverse transcription kit (Toyobo Co., Ltd., Osaka, Japan). The CDK4, MYB and SIRTI genes were amplified using the ABI 7500 real-time PCR system, with the glyceraldehyde 3-phosphate dehydrogenase gene $(G A P D H)$ serving as an internal control. The amplification was performed as follows: one cycle of pre-denaturation at $95^{\circ} \mathrm{C}$ for $5 \mathrm{~min}$, followed by 40 cycles of denaturation at $95^{\circ} \mathrm{C}$ for $15 \mathrm{sec}$ and extension at $60^{\circ} \mathrm{C}$ for $1 \mathrm{~min}$. Sequences of the upstream and downstream primers used in these reactions were: $C D K 4,5$ '-GCC CAA TCA GGT CAA AGA TT-3' and 5'-ACA TGT GGA GTG TTG GCT GT-3'; $M Y B$, 5'-TGT TCC ATT CTG TTC CAC CA-3' and 5'-GAC TAT GAT GGG CTG CTT CC-3'; SIRT1, 5'-TGA CAG AGA GAT GGC TGG AA-3' and 5'-CCA GAT CCT CAA GCG ATG TT-3'; GAPDH, 5'-CGA GAT CCC TCC AAA ATC AA-3' and 5'-TTC ACA CCC ATG ACG AAC AT-3'.

MTT assay. Cells were cultured in 96-well plates. Following transfection, $20 \mu \mathrm{l}$ of $5 \mathrm{mg} / \mathrm{ml}$ MTT (Sigma-Aldrich, St. Louis, MO, USA) was added to each well. After incubation at $37^{\circ} \mathrm{C}$ for $4 \mathrm{~h}, 50 \mu \mathrm{l}$ of the supernatant was carefully removed and $150 \mu$ dimethyl sulfoxide (DMSO; Sigma-Aldrich) was added. Samples were agitated for $10 \mathrm{~min}$, and absorbance was measured at $550 \mathrm{~nm}$ on a microplate reader (SPECTRA Fluor, Tecan, Männedorf, Switzerland). Three replicated wells were measured per group. The BC group contained no cells.

Cell viability test. The trypan blue assay was used to assess the viability of HL-60 cells. Briefly, the HL-60 cell suspension was mixed with $0.4 \%$ trypan blue solution (9:1) (Huamei Biotechnology Co., Wuhan, China). Dead cells were stained blue and living cells remained unstained. Unstained and stained cells were counted within $3 \mathrm{~min}$. HL-60 cell viability = living cells/(living cells + dead cells) x100\%.

Western blot analysis. Cells were washed twice with ice-cold PBS and then treated with lysis buffer for $30 \mathrm{~min}$ at $4^{\circ} \mathrm{C}$. The supernatants were centrifuged at $12,000 \mathrm{xg}$ for $30 \mathrm{~min}$ at $4^{\circ} \mathrm{C}$. Protein samples were electrophoresed on 7.5\% SDS-PAGE gels and transferred to polyvinylidene fluoride (PVDF) membranes. 
Table I. Analysis of mRNA levels of $C D K 4$ and $M Y B$ in peripheral blood of pediatric patients with acute leukemia (AL).

\begin{tabular}{|c|c|c|c|c|c|c|}
\hline Variables & & No. $(\%)$ & $M Y B^{a}$ & $\mathrm{P}$ & $C D K 4^{a}$ & $\mathrm{P}$ \\
\hline Age & $\begin{array}{l}<3 \text { years } \\
>3 \text { years }\end{array}$ & $\begin{array}{r}8(27.59) \\
21(72.42)\end{array}$ & $\begin{array}{l}1.26 \pm 0.37 \\
2.69 \pm 0.26\end{array}$ & $\mathrm{P}<0.05$ & $\begin{array}{l}1.11 \pm 0.45 \\
1.78 \pm 0.33\end{array}$ & $\mathrm{P}>0.05$ \\
\hline Gender & $\begin{array}{c}\text { Male } \\
\text { Female }\end{array}$ & $\begin{array}{l}12(41.38) \\
17(58.62)\end{array}$ & $\begin{array}{l}3.40 \pm 0.21 \\
0.01 \pm 0.32\end{array}$ & $P>0.05$ & $\begin{array}{l}1.62 \pm 0.41 \\
1.60 \pm 0.31\end{array}$ & $\mathrm{P}>0.05$ \\
\hline WBCs & $\begin{array}{l}\leq 50 \\
>50\end{array}$ & $\begin{array}{r}22(41.38) \\
7(24.14)\end{array}$ & $\begin{array}{l}5.64 \pm 0.38 \\
0.50 \pm 0.29\end{array}$ & $\mathrm{P}<0.01$ & $\begin{array}{l}1.61 \pm 0.28 \\
1.44 \pm 0.58\end{array}$ & $\mathrm{P}>0.05$ \\
\hline AL Type & $\begin{array}{c}\text { ALL } \\
\text { ANLL }\end{array}$ & $\begin{array}{r}25(86.07) \\
4(13.80)\end{array}$ & $\begin{array}{l}3.64 \pm 0.15 \\
1.24 \pm 0.31\end{array}$ & $P>0.05$ & $\begin{array}{l}1.78 \pm 0.31 \\
0.91 \pm 0.39\end{array}$ & $\mathrm{P}>0.05$ \\
\hline Risk & $\begin{array}{c}\text { HR } \\
\text { IR } \\
\text { SR }\end{array}$ & $\begin{array}{r}7(24.14) \\
7(24.13) \\
15(52.72)\end{array}$ & $\begin{array}{l}1.35 \pm 0.30 \\
2.29 \pm 0.41 \\
2.91 \pm 0.30\end{array}$ & $P>0.05$ & $\begin{array}{l}1.46 \pm 0.40 \\
1.76 \pm 0.23 \\
1.39 \pm 0.41\end{array}$ & $\mathrm{P}>0.05$ \\
\hline Prednisone response ${ }^{\mathrm{b}}$ & $\begin{array}{l}\text { Sensitive } \\
\text { Insensitive }\end{array}$ & $\begin{array}{r}18(69.23) \\
8(30.78)\end{array}$ & $\begin{array}{l}2.10 \pm 0.31 \\
4.20 \pm 0.29\end{array}$ & $P>0.05$ & $\begin{array}{l}1.20 \pm 0.28 \\
2.35 \pm 0.30\end{array}$ & $\mathrm{P}>0.05$ \\
\hline Immunophenotype ${ }^{c}$ & $\begin{array}{l}\mathrm{B} \\
\mathrm{T}\end{array}$ & $\begin{array}{r}19(76.00) \\
6(24.00)\end{array}$ & $\begin{array}{r}3.45 \pm 0.34 \\
10.03 \pm 0.20\end{array}$ & $\begin{array}{l}P>0.05 \\
P>0.05\end{array}$ & $\begin{array}{l}1.46 \pm 0.36 \\
2.15 \pm 0.43\end{array}$ & $\mathrm{P}>0.05$ \\
\hline Gene fusion test ${ }^{\mathrm{d}}$ & $\begin{array}{l}\text { Positive } \\
\text { Negative }\end{array}$ & $\begin{array}{r}6(22.22) \\
11(40.74)\end{array}$ & $\begin{array}{l}1.39 \pm 0.36 \\
5.22 \pm 0.26\end{array}$ & & $\begin{array}{l}1.37 \pm 1.37 \\
1.73 \pm 0.43\end{array}$ & $\mathrm{P}>0.05$ \\
\hline
\end{tabular}

${ }^{\mathrm{a}} 2^{-\Delta \Delta \mathrm{C}_{\mathrm{t}}} \pm \mathrm{SD}$ values; ${ }^{\mathrm{b}}$ three samples lost in the follow-up; 'four samples lost in the follow-up; ${ }^{\mathrm{d}} 12$ samples not subjected to the test. $C D K 4$, cyclin-dependent kinase 4; WBCs, white blood cells; ALL, acute lymphoblastic leukemia; ANLL, acute non-lymphocytic leukemia; HR, high risk; IR, intermediate risk; SR, standard risk.

Non-specific reactivity was blocked by incubating with $5 \%$ non-fat dry milk in a mixture of Tris-buffered saline and Tween 20 (TBS/T) for $1 \mathrm{~h}$ at room temperature. The membrane was then treated with primary antibodies targeting CDK4, MYB and SIRT1 proteins. Each sample was also treated with anti- $\beta$-actin antibody (Sigma-Aldrich) as a control.

Statistical analysis. Data are expressed as mean \pm standard deviation (SD) and were analyzed by Student's t-tests. Pearson's correlation analysis was used to determine the relationship between expression of miRNA-34a and that of $C D K 4, M Y B$ and SIRT1. $\mathrm{P}<0.05$ was considered to indicate statistically significant differences. The analyses were performed with the SAS 9.1 statistical software (SAS Institute, Cary, NC, USA).

\section{Results}

In vivo expression of $m i R-34 a, C D K 4, M Y B$ and SIRT1. The expression of miRNA-34a in acute leukemia children patients was significantly lower compared to healthy controls $(\mathrm{P}<0.01)$. The miR-34a levels were highly variable among patients, ranging from undetectable to $35 \%$ of average control. The average relative expression of miR-34a in AL patients was only $14.93 \%$ of the healthy controls ( 0.66 of $2^{-\Delta \Delta \text { ct }}$ vs. 3.11 of $2^{-\Delta \Delta \mathrm{ct}}$ in controls).

The expression levels of $C D K 4$ and $M Y B$ in the peripheral blood of AL children were significantly higher compared to those of healthy children $(\mathrm{P}<0.01)$, while the expression of SIRT1 showed no significant difference between the two

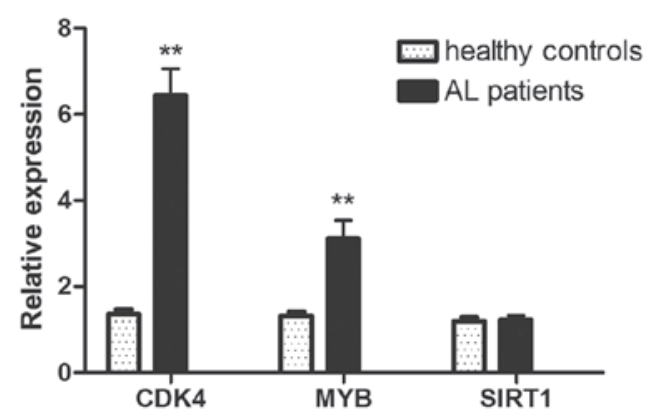

Figure 1. The mRNA levels of $M Y B$, cyclin-dependent kinase 4 (CDK4), and silent information regulator 1 (SIRT1) in acute leukemia (AL) children and healthy controls. Compared to healthy controls, the expression of $M Y B$ and $C D K 4$ was significantly increased $\left({ }^{* *} \mathrm{P}<0.05\right)$.

groups (Fig. 1). Sub-group analysis for AL children showed that $M Y B$ expression was significantly higher in patients $>3$ years of age compared to patients $<3$ years of age, and a similar result was obtained when comparing patients with WBC counts above and below $5 \times 10^{10} / 1$ (Table I). There was no significant difference in the expression of $C D K 4$ and $M Y B$ between subgroups when they were classified by age (for $C D K 4$ ), gender, $\mathrm{AL}$ subtype, immunophenotype, WBC count in peripheral blood at diagnosis (for $C D K 4$ ), risk factors, appearance of fusion genes, and response to prednisone therapy.

Correlation analysis. Pearson's correlation analysis demonstrated that the expression of miRNA-34a was negatively 
A

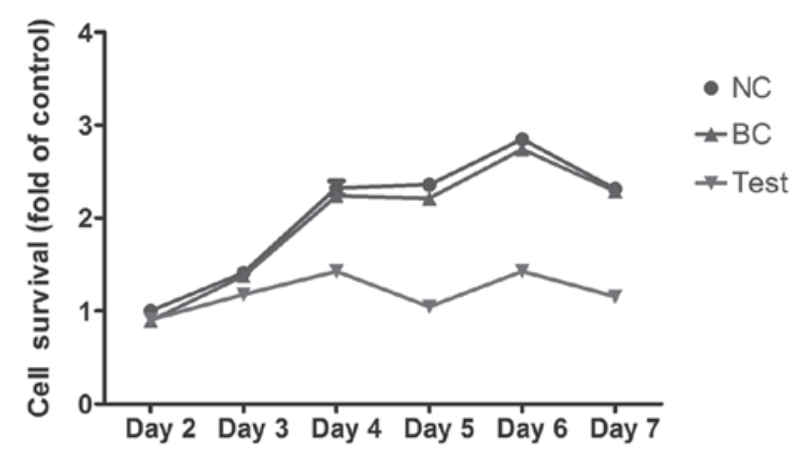

B

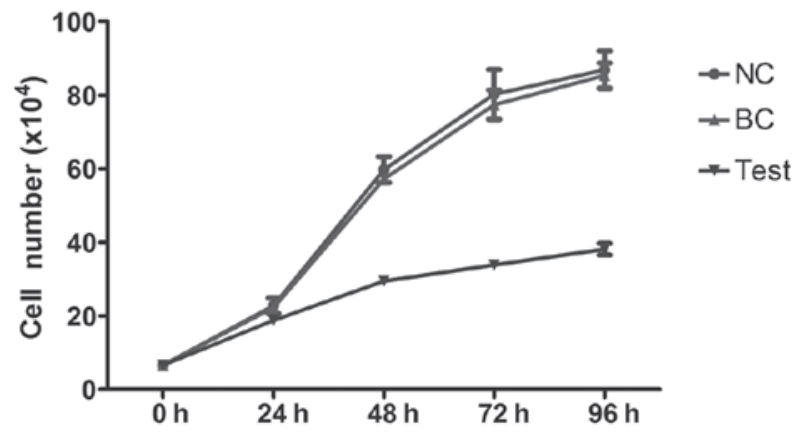

Figure 2. Time-dependent changes in the proliferation of HL-60 cells transfected with different miRNAs. Proliferation was assessed by the (A) MTT and (B) trypan blue assays. The blank control (BC) cells were not transfected by miRNAs, the negative control (NC) cells were transfected with scrambled miRNA and the test cells were transfected with microRNA-34a (miRNA34a).

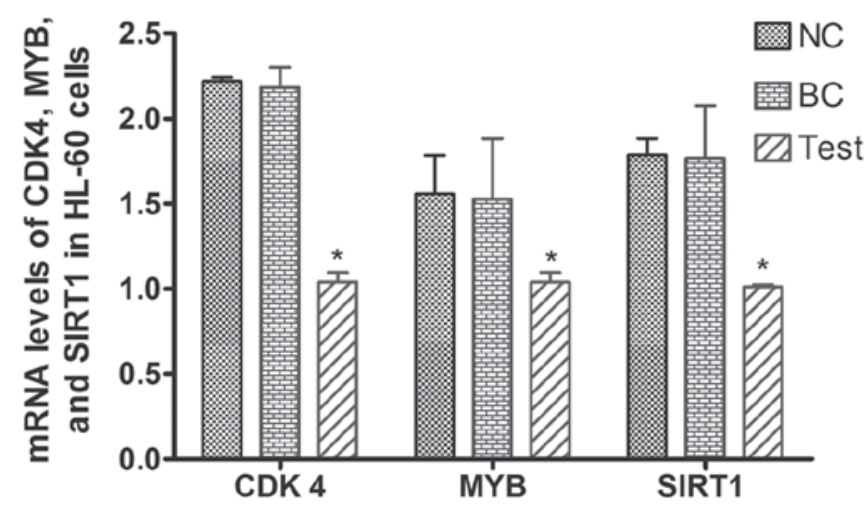

Figure 3. The expression of $M Y B$, cyclin-dependent kinase 4 (CDK4), and silent information regulator 1 (SIRT1) genes in HL-60 cells after transfection with different miRNAs. ${ }^{*} \mathrm{P}<0.05$, compared to the blank control $(\mathrm{BC})$ group of non-transfected cells and the negative control (NC) group, where cells were transfected with scrambled miRNA. Cells of the test group were transfected with microRNA-34a (miRNA34a).

correlated with the mRNA level of $C D K 4$ and $M Y B(\mathrm{P}<0.01)$, but not with that of SIRTI ( $\mathrm{P}>0.05)$ (Table II).

Viability of HL-60 cells following miRNA-34a transfection. Fig. 2A shows the viability of HL-60 cells as assessed by the MTT assay. The BC group had the highest viability in all tested time-points, while the test group had the lowest viability, suggesting that exogenous miRNA-34a can inhibit the viability of HL-60 cells. A similar result was obtained from trypan blue staining assays, which demonstrated that miRNA-34a effectively inhibits the proliferation of HL-60 cells (Fig. 2B).
Table II. Correlation analysis between miR-34a and $C D K 4$, $M Y B, S I R T 1$ expression in AL patients.

\begin{tabular}{lccc}
\hline Parameters & $C D K 4^{\mathrm{a}}$ & MYB $^{\mathrm{a}}$ & SIRTI $^{\mathrm{a}}$ \\
\hline $\mathrm{R}^{2}$ & 0.933 & 0.887 & 0.305 \\
$\mathrm{P}$ & 0.000 & 0.000 & 0.108
\end{tabular}

afrom Pearson's correlation analysis. $\mathrm{R}^{2}$ denotes the coefficient of correlation of miR-34a expression with that of genes shown in the columns. miR-34a, microRNA-34a; CDK4, cyclin-dependent kinase 4; SIRT1, silent information regulator 1; AL, acute leukemia.

$\mathbf{A}$

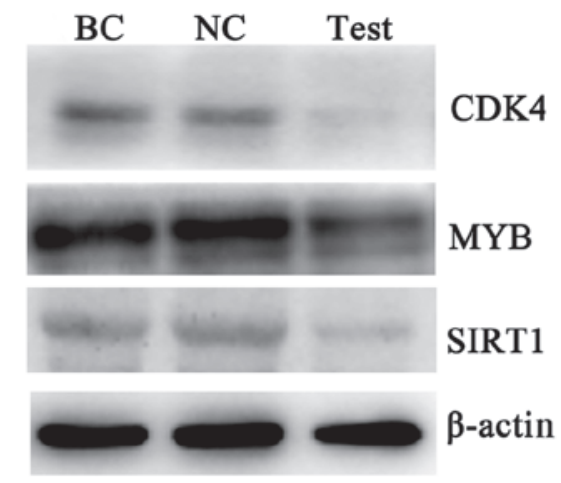

B

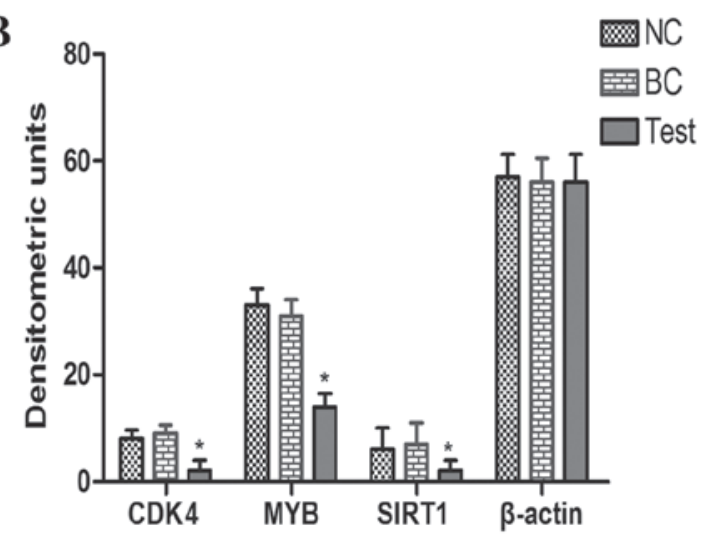

Figure 4. The protein level of MYB, cyclin-dependent kinase 4 (CDK4) and silent information regulator 1 (SIRT1) in HL-60 cells after transfection with different miRNAs. (A) Representative picture of western blotting and (B) quantification of protein levels. " $\mathrm{P}<0.05$, compared to controls. The blank control (BC) contained no cells, the negative control (NC) cells were transfected with scrambled miRNA and the test cells were transfected with microRNA-34a (miRNA34a).

Expression of CDK4, MYB and SIRT1 in HL-60 cells following transfection. We measured the mRNA expression of CDK4, $M Y B$ and SIRT1 $48 \mathrm{~h}$ after transfection of HL-60 cells with miRNA. The levels of these genes were significantly lower in the miR-34a-transfected (test) group compared to the other two groups $(\mathrm{P}<0.05)$, while there was no difference in their levels when $\mathrm{BC}$ and $\mathrm{NC}$ groups were compared (Fig. 3). Compared to the NC group (transfected with scrambled miRNA), the expression of $C D K 4, M Y B$, and SIRT1 was decreased by $43.3,53.2$ and $33.5 \%$, respectively. Western blot analysis also demonstrated that exogenous miRNA-34a can reduce the protein level of CDK4, MYB and SIRT1 proteins (Fig. 4). 


\section{Discussion}

Tumorigenesis is a complex biological process that involves gene mutations and aberrant expression. Characterizing differences in the expression of miRNA target genes in cancer patients is of high value in cancer research. Rücker et al (20) reported the aberrant expression of miR-34a in acute myeloid leukemia patients with complex karyotype (CK-AML). The authors showed that in the clinic, low miR-34a expression and tumor protein p53 (TP53) alterations were associated with resistance to chemotherapy and inferior outcome of the treatment. Notably, in TP53-unaltered CK-AML patients, high miR-34a expression predicted inferior overall survival (OS), whereas in TP53-biallelic-altered CK-AML patients, high miR-34a expression predicted better OS. Thus, targeted treatment based on the expression status of cells for miR-34a is necessary.

Numerous miRNAs have been directly associated with the development of human tumors such as lung, breast, liver and colon cancer, as well as leukemia (21). Some of these miRNAs act as tumor suppressors. For example, He et al (7) reported in 2007 that miRNA-34 molecules (miR-34a, miR-34b and $\mathrm{miR}-34 \mathrm{c}$ ) are direct targets of the tumor suppressor protein $\mathrm{p} 53$, and suggested a new mechanism explaining the p53-mediated inhibition of mammalian cell growth: the evolutionally conserved miR-34s may respond to DNA damage and tumor formation via a 553 -dependent pathway. The authors presented evidence showed that alternatively spliced miR-34 may exert the same biological effects as p53, such as the induction of cell cycle arrest and apoptosis, probably via the downregulation of mitogenic and anti-apoptotic genes.

Pediatric leukemia is unique for its clinical and biological properties: response to treatment, cure rate, and immunophenotype. The development of leukemia relates not only to chromosome abnormalities and gene mutations, but is also closely associated with epigenetic characteristics and miRNA expression profiles. Previous studies showing that miRNAs can modulate the expression of target genes at the post-transcriptional level $(22,23)$ and that miRNA expression is also subject to epigenetic regulation $(24,25)$ contributed to the clinical application of miRNAs.

A number of genes, including $C D K 4$, CDK6, MYB, SIRT1, and cell cycle-associated protein 2 , has been shown to be targeted by miR-34 $(11,26,27)$. The current study showed that the expression of $C D K 4$ and $M Y B$ in peripheral blood cells is significantly higher in children with acute leukemia compared to healthy ones. Stratified (sub-group) analyses showed that the expression of $M Y B$ in children with acute leukemia $<3$ years old is significantly higher compared to that observed in children $>3$ years, and it was also significantly higher in children with peripheral WBC counts $>5 \times 10^{10} / 1$ at diagnose compared to those with WBC counts $\leq 5 \times 10^{10} / 1$, who may have lower miRNA-34a expression. These findings strongly suggest that the expression level of $C D K 4$ and $M Y B$ may be associated with the development of leukemia. Aberrant expression of $C D K 4$ was previously shown to associate with differentiation of liposarcoma and enhanced proliferation of laryngeal cancer cells $(28,29)$. In addition, Weber et al (30) showed that alternative splicing of the c- $M Y B$ mRNA resulting in enhanced $M Y B$ expression occurred in hematologic malignancies and caused excessive proliferation and differentiation of the malignant cells.

Yamakuchi et al (5) found that there is a 3'-UTR binding site in the SIRT1 gene sequence for miR-34a, and confirmed that SIRT1 is a target of miR-34a by luciferase reporter gene assays, and by showing that miR-34a causes SIRT1 mRNA degradation. In our study, there was no significant difference in SIRT1 expression between leukemic and healthy controls, but the relatively small number of studied patients may have affected this result. It is therefore worth extending the present study in a larger population.

In conclusion, the development of leukemia involves the activation of multiple genes and related signaling pathways. Our study has demonstrated that miRNA-34a inhibits HL-60 cell proliferation by downregulating the expression of $C D K 4$, $M Y B$ and SIRT1. Thus, miR-34 may target these genes and play an important role in leukemic cell proliferation. Intervention with endogenous miR-34a may be a suitable treatment strategy.

\section{Acknowledgements}

This study was supported by the China National grant 863, permit no. 2012AA020804.

\section{References}

1. Yamakuchi M and Lowenstein CJ: MiR-34, SIRT1 and p53: the feedback loop. Cell Cycle 8: 712-715, 2009.

2. Rokhlin OW, Scheinker VS, Taghiyev AF, Bumcrot D, Glover RA and Cohen MB: MicroRNA-34 mediates AR-dependent p53-induced apoptosis in prostate cancer. Cancer Biol Ther 7: 1288-1296, 2008.

3. Paris R, Henry RE, Stephens SJ, McBryde M and Espinosa JM: Multiple p53-independent gene silencing mechanisms define the cellular response to p53 activation. Cell Cycle 7: 2427-2433, 2008.

4. Mert U, Ozgür E, Tiryakioglu D, Dalay N and Gezer U: Induction of p53-inducible microRNA miR-34 by gamma radiation and bleomycin are different. Front Genet 3: 220, 2012.

5. Yamakuchi M, Ferlito M and Lowenstein CJ: miR-34a repression of SIRT1 regulates apoptosis. Proc Natl Acad Sci USA 105: 13421-13426, 2008.

6. Tazawa $H$, Tsuchiya $N$, Izumiya $M$ and Nakagama $H$ : Tumor-suppressive miR-34a induces senescence-like growth arrest through modulation of the E2F pathway in human colon cancer cells. Proc Natl Acad Sci USA 104: 15472-15477, 2007.

7. He X, He L and Hannon GJ: The guardian's little helper: microRNAs in the p53 tumor suppressor network. Cancer Res 67: 11099-11101, 2007.

8. Tarasov V, Jung P, Verdoodt B, et al: Differential regulation of microRNAs by $\mathrm{p} 53$ revealed by massively parallel sequencing: miR-34a is a p53 target that induces apoptosis and G1-arrest. Cell Cycle 6: 1586-1593, 2007.

9. Kumamoto K, Spillare EA, Fujita K, et al: Nutlin-3a activates p53 to both down-regulate inhibitor of growth 2 and up-regulate mir-34a, mir-34b, and mir-34c expression, and induce senescence. Cancer Res 68: 3193-3203, 2008.

10. He L, He X, Lim LP, et al: A microRNA component of the p53 tumour suppressor network. Nature 447: 1130-1134, 2007.

11. Navarro F, Gutman D, Meire E, et al: miR-34a contributes to megakaryocytic differentiation of K562 cells independently of p53. Blood 114: 2181-2192, 2009.

12. Li L, Wu J, Sima X, et al: Interactions of miR-34b/c and TP-53 polymorphisms on the risk of nasopharyngeal carcinoma. Tumour Biol 34: 1919-1923, 2013.

13. Ji Q, Hao X, Meng Y, et al: Restoration of tumor suppressor miR-34 inhibits human p53-mutant gastric cancer tumorspheres. BMC Cancer 8: 266, 2008.

14. Ji Q, Hao X, Zhang M, et al: MicroRNA miR-34 inhibits human pancreatic cancer tumor-initiating cells. PLoS One 4: e6816, 2009. 
15. Pang Y, Young CY and Yuan H: MicroRNAs and prostate cancer. Acta Biochim Biophys Sin (Shanghai) 42: 363-369, 2010.

16. Dalgard CL, Gonzalez M, deNiro JE and O'Brien JM: Differential microRNA-34a expression and tumor suppressor function in retinoblastoma cells. Invest Ophthalmol Vis Sci 50: 4542-4551, 2009.

17. Zenz T, Mohr J, Eldering E, et al: miR-34a as part of the resistance network in chronic lymphocytic leukemia. Blood 113 3801-3808, 2009.

18. Wang J, Liu L, Xie L, Xiang G and Zhou Y: Induction of differentiation-specific miRNAs in TPA-induced myeloid leukemia cells through MEK/ERK activation. Int J Mol Med 31: 59-66, 2013.

19. Vissers MC, Jester SA and Fantone JC: Rapid purification of human peripheral blood monocytes by centrifugation through Ficoll-Hypaque and Sepracell-MN. J Immunol Methods 110: 203-207, 1988.

20. Rücker FG, Russ AC, Cocciardi S, et al: Altered miRNA and gene expression in acute myeloid leukemia with complex karyotype identify networks of prognostic relevance. Leukemia 27: 353-361, 2013.

21. Visone R and Croce CM: MiRNAs and cancer. Am J Pathol 174: 1131-1138, 2009.

22. Kelly L,Bryan K,Kim SY, et al: Post-transcriptional dysregulation by miRNAs is implicated in the pathogenesis of gastrointestinal stromal tumor [GIST]. PLoS One 8: e64102, 2013.
23. Tuccoli A, Poliseno L and Rainaldi G: miRNAs regulate miRNAs: coordinated transcriptional and post-transcriptional regulation. Cell Cycle 5: 2473-2476, 2006.

24. Isken F, Steffen B, Merk S, et al: Identification of acute myeloid leukaemia associated microRNA expression patterns. Br J Haematol 140: 153-161, 2008.

25. Garzon R, Heaphy CE, Havelange V, et al: MicroRNA 29b functions in acute myeloid leukemia. Blood 114: 5331-5341, 2009.

26. Sun F, Fu H, Liu Q, et al: Downregulation of CCND1 and CDK6 by miR-34a induces cell cycle arrest. FEBS Lett 582: 1564-1568, 2008.

27. Tivnan A, Tracey L, Buckley PG, Alcock LC, Davidoff AM and Stallings RL: MicroRNA-34a is a potent tumor suppressor molecule in vivo in neuroblastoma. BMC Cancer 11: 33, 2011.

28. Pilotti S, Della Torre G, Mezzelani A, et al: The expression of MDM2/CDK4 gene product in the differential diagnosis of well differentiated liposarcoma and large deep-seated lipoma. Br J Cancer 82: 1271-1275, 2000.

29. Dong Y, Sui L, Sugimoto K, Tai Y and Tokuda M: Cyclin D1-CDK4 complex, a possible critical factor for cell proliferation and prognosis in laryngeal squamous cell carcinomas. Int $\mathrm{J}$ Cancer 95: 209-215, 2001.

30. Weber BL, Westin EH and Clarke MF: Differentiation of mouse erythroleukemia cells enhanced by alternatively spliced c-MYB mRNA. Science 249: 1291-1293, 1990. 